\title{
Mapeamento dos Estudos Sobre Educação Estatística com Uso Pedagógico das Tecnologias Digitais em Periódicos Nacionais
}

\section{Mapping of Studies on Statistical Education with Pedagogical Use of Digital Technologies in National Journals}

\author{
Reinaldo Feio Lima*a; Marlúbia Corrêa de Paula ${ }^{\mathrm{b}}$ \\ ${ }^{a}$ Universidade Federal do Sul e Sudeste do Pará, PA, Brasil. \\ ${ }^{\text {b}}$ Universidade Estadual de Santa Cruz. BA, Brasil. \\ *E-mail: reinaldo.lima@unifesspa.edu.br
}

\begin{abstract}
Resumo
Neste artigo, apresentamos parte dos resultados de uma pesquisa que vem sendo realizada por um grupo de pesquisa, que pretende analisar o uso das tecnologias digitais na Educação Estatística em revistas eletrônicas brasileiras, com publicação de edições especiais desse campo de estudo, a fim de identificar as produções e de que forma tal uso é proposto nesses textos. A investigação que trazemos é desenvolvida segundo a abordagem qualitativa, por meio de um mapeamento crítico realizado com base nos vieses da Metanálise. Os procedimentos da Análise de Conteúdo fundamentam a análise de cada texto. Como resultados, identificamos que sete textos incluíram as tecnologias digitais na Educação Estatística, fazendo uso de softwares como apoio às aulas e na comunicação entre professores e estudantes. Concluímos que o uso das tecnologias digitais ainda tem inserção tímida na área de Educação Estatística e prevaleceram reflexões sobre o foco na aprendizagem dos estudantes.
\end{abstract}

Palavras-chave: Educação Estatística. Tecnologias Digitais. Mapeamento.

\begin{abstract}
In this article, we present part of the results of research, which intends to analyze the use of digital technologies in Statistical Education in Brazilian electronic journals, with the publication of special editions of this field of study, to identify the productions and how such use is proposed in these texts. The investigation that we present is developed according to a qualitative approach, through a critical mapping carried out based on the biases of Meta-analysis. Content Analysis procedures support the analysis of each text. As a result, we identified that seven texts included digital technologies in Statistical Education, using software in classes, and communication between teachers and students. We conclude that the use of digital technologies still has a timid insertion in Statistical Education and the reflections focused on student learning prevailed.
\end{abstract}

Keywords: Statistical Education. Digital Technologies. Mapping.

\section{Introdução}

Este $\operatorname{artigo}^{1}$ apresenta resultados parciais de uma pesquisa denominada "Mensagem Pedagógica representada em textos brasileiros sobre Educação Estatística: um mapeamento", iniciada em março 2020 pelo grupo de pesquisas "Grupo de Pesquisa em Educação Matemática", do Instituto de Engenharia do Araguaia (IEA), da Universidade Federal do Sul e Sudeste do Pará (UNIFESSPA).

Em relação ao uso de siglas que determinam as tecnologias atuais, observamos que as publicações pontuam ora um uso, ora outro. Isso, sob o ponto de vista de Costa, Duqueviz e Pedrosa (2015); Baranauskas e Valente (2013), se deve ao fato de que algumas tecnologias são mais atuais (computadores, smartfones, etc.) do que outras (Mimeógrafos, TV, etc.). Para esses autores, a atualidade das tecnologias fica demarcada pelo uso de termos escritos como Tecnologias Digitais de
Informação e Comunicação (TDIC). Essa explicitação é conveniente, pois os trabalhos que compõem o corpus deste artigo, naturalmente, ainda variam o uso dessas siglas. No grupo IEA, a forma de se referir a essas tecnologias tem recaído sobre o uso de Tecnologias Digitais (TD).

A partir das considerações acima e por não haver uma razão que contrarie essa diversidade observamos que, no cenário internacional, as TD têm constituído um dos focos da nova geração de políticas de educação na União Europeia, sendo um dos eixos prioritários da Agenda 2020 (Pinto \& Leite, 2020). Para efeitos de análise, assumimos neste artigo a definição de Tecnologias Digitais referida por Selwyn (2016, p.124).

Tecnologias digitais podem incluir, mas não estão limitadas a: computadores, tablets, smartphones, Facebook, Moodle, serviços online da Biblioteca, Google, Youtube, escrever ensaios no Microsoft Word, etc. Tecnologia digital também permite às pessoas acederem à internet, não só a

\footnotetext{
1 Uma versão preliminar deste artigo foi apresentada no I Encontro Nacional Online de Professores que Ensinam Matemática, realizado nos dias 16, 18 e 19 de novembro de 2020, na UNEMATL/MT.
} 
partir de casa, mas também a partir de qualquer outro local através do uso de dispositivos móveis.

Além disso, as TD têm assumido um papel relevante como mediadoras nos processos de ensino e aprendizagem ativos e autônomos dos estudantes em diferentes níveis, uma vez que eles vivem imersos em mídias digitais em todos os aspectos da sua vida e continuarão a usá-las nas suas experiências de integração e participação familiar, acadêmica e social (Bates, 2017). Com a inserção mais intensa do uso das TD nos processos de ensino, que antes estavam restritos em locais, entre outros, descritos como escolas e universidades, as formas de acesso às informações foram ampliadas. Pois, tudo aquilo que antes dependia do professor, do livro e de suas interlocuções para ser posto em discussão agora está ao dispor de todo indivíduo que tenha acesso a um computador conectado à rede mundial. Nesse sentido, o professor passa a ser aquele que auxilia nos procedimentos de aprendizagem que transformam a informação em conhecimento.

Conforme Santaella (2013), o indivíduo que tem acesso as TD, em todo lugar e tempo, passou a ser conhecido como um utilizador de uma comunicação ubíqua, o que aos poucos produz uma certa repercussão na cultura presente nas questões educacionais. No entanto, tudo isso ainda se faz presente apenas para aqueles que possuem intenso acesso às TD.

Por isso, quando este artigo assume o compromisso de apresentar os resultados parciais de uma pesquisa denominada "Mensagem Pedagógica representada em textos brasileiros sobre educação estatística: um mapeamento", pelo grupo de pesquisas "Grupo de Pesquisa em Educação Matemática", o faz a partir do reconhecimento dessa situação, entendendo-a como um recorte, no momento em que alia a esta temática o uso de TD. Nesse sentido, considera que o público que tem acesso às TD, está sendo descrito, se situa nas universidades e é por essa subsidiada, por meio da presença de seus sinais de Wireless Fidelity, popularmente conhecida como Wi-Fi. Dessa forma, não desconsideramos a situação do contexto brasileiro, em que o aceso ao uso de TD ainda é uma meta a ser atingida em algumas regiões.

Desse modo, a participação familiar, e posteriormente acadêmica, leva a outras tecnologias, como as de comunicação interpessoal, que também são muitas vezes utilizadas pelos estudantes no suporte à aprendizagem (Morais, 2012), o que indica possibilidades de uso de ferramentas que combinam fins pessoais e fins acadêmicos (Pombo, 2016, Batista, 2011). Eis aqui o que se postula em relação esses fins que se combinam e assim são ditos ubíquos. Com essa forma de assumir o uso das TD, “as mesmas mídias que fornecem o acesso são também mídias de comunicação. Redes sem fio e, consequentemente, móveis são a tônica tecnológica do momento" (Santaella, 2013, p. 15).

Esse tipo de tecnologia, que conecta tanto os estudantes na vida pessoal como nas escolas e universidades quanto os professores, sem distinção de ambientes, é o que Santaella
(2013) chama de tecnologia ubíqua. Com esse modo de entender o quanto a tecnologia tem uma natureza com capacidade de incorporar-se ao cenário de vida, não distinguindo quanto a usos, quanto a fluxo, indo do pessoal ao profissional, é que esse uso transformou a própria comunicação em muitas de suas dimensões. A exemplo disso, é facilmente comprovável que enquanto contatos estabelecidos do ponto de vista quantitativo, todos aqueles que têm acesso ao $W i-F i$ estão permanentemente imprimindo a sua rotina diária, o rótulo do que tem sido descrito como cibridismo (Gabriel, 2013).

No cibridismo, "não somos mais on ou off-line - somos on e off ao mesmo tempo, simbioticamente, formando um ser maior que o nosso corpo/cérebro biológico, nos expandindo para todo tipo de dispositivo e abrangendo outras mentes e corpos" (Gabriel, 2013, p.58). Em razão dessas possibilidades, tanto professores quanto estudantes se encontram na condição de ser cíbrido o que impõe um processo de transformação à própria forma de realizar o ensino de Estatística, dentro do que se entende por EE. Pois, nesse contexto, "somos abordados por qualquer propósito a qualquer hora e podemos estar em contato com outras pessoas quaisquer que sejam suas condições de localização e afazeres no momento, o que nos transmite um sentimento de onipresença" (Santaella, 2013, p.16).

Portanto, quanto ao uso das TD no suporte à aprendizagem, consideramos todas as atividades que podem conduzir ou contribuir para a aprendizagem por parte dos estudantes e professores, pois "todos podem ser receptores, produtores e emissores de conteúdo. Especialmente, os jovens integram-se a esse movimento, utilizando intensamente seus aparelhos de telefone celular, seus smartphones para comunicar" (Cordeiro \& Bonilla, 2015, p. 260).

Estudos nacionais também identificaram quais são as TD que os estudantes em diferentes níveis de ensino usam com mais frequência em contexto de aprendizagem formal e para fins pessoais (Santos, 2019; Valim, 2019; Estevam, 2010) entre outras. No tocante à educação, as TD baseadas na internet, como são, por exemplo, as ferramentas Web 2.0 ou as redes sociais, constituem recursos pedagógicos capazes de promover interações entre estudantes e professores(as) em contexto de ensino e de aprendizagem, proporcionando mais partilha e autonomia pessoal (Norman et al., 2013; Sleeman, Lang \& Lemon, 2016), já que "acessar, reconstruir, emitir informações e conteúdos ganham dinâmicas diferenciadas no cotidiano das pessoas comuns com o advento das tecnologias da informação e comunicação, mais intensamente a partir da Web 2.0" (Cordeiro \& Bonilla, 2015, p. 260).

Além disso, dispositivos como smartphones, tablets, leitores eletrônicos e apps móveis têm-se destacado como ferramentas pedagógicas emergentes de apoio à aprendizagem no Ensino Básico e Superior (Aresta, Pedro \& Santos, 2015; Stevenson \& Hedberg, 2017), apoiando e transformando as interações entre professores e estudantes e entre pares (Becker, 2017).

No tocante à Educação Estatística (EE), a empregabilidade 
das TD como recurso pedagógico, ao longo da atividade estatística, passa a agregar valor à utilização destas tecnologias no contexto educativo, uma vez que ocorre a intencionalidade pedagógica (Valcável \& Repiso, 2003). Portanto, seu uso deve ser mediado pelo(a) professor(a) diante da necessidade de objetivos e conteúdo, escolha da TD e avaliação dos processos de ensino e de aprendizagem (Silva, 2006), uma vez que pode ter efeitos no tempo dedicado à interação entre estudantes e docentes, continuando para além das paredes da sala de aula e muro das escolas, em um processo de envolvimento, partilha de conteúdos e materiais de estudo e de comunicação (Pinto \& Leite, 2020). Com isso, inclusive a expressão "muros da escola" torna-se obsoleta - para quem tem acesso a computadores e internet, entre outros dispositivos conectados.

No âmbito desta disseminação do uso de TD, sabemos que, no cenário brasileiro, a inserção da $\mathrm{EE}$ nos meios acadêmicos "foi lenta e tardia (...) isto, em parte, se deve ao fato de ser a Estatística (assim como a própria Matemática) uma ciência preterida em favor de estudos literários e jurídicos, considerados de maior prestígio e tradição erudita" (Santos, 2014, p. 3). No entanto, com a publicação dos Parâmetros Curriculares Nacionais (PCN), em 1998, no Brasil, os estudos de Estatística, Combinatória e Probabilidade ganharam espaço e visibilidade com o bloco Tratamento da Informação (Lopes, 1998). Recentemente, a Base Nacional Comum Curricular (BNCC) trouxe contribuições para o processo de ensino e aprendizagem da Educação Estatística, já que

ela propõe a abordagem de conceitos, fatos e procedimentos presentes em situações-problema da vida cotidiana, das ciências e da tecnologia. Assim, todos os cidadãos precisam desenvolver habilidades para coletar, representar, interpretar e organizar dados de uma variedade de contextos, de maneira a fazer julgamentos bem fundamentados e tomar as decisões adequadas. Isso inclui raciocinar e utilizar conceitos, representações e índices estatísticos para descrever, explicar e predizer fenômenos. (Brasil, 2017, p. 272).

Para Cazorla, Silva e Santana (2018), este viés busca desenvolver habilidades/competências que possibilitem coletar/produzir, organizar e interpretar dados em uma variedade de contextos proporcionados pelo contato com livros didáticos, jornais, revistas e mídias digitais, entre outros. Tudo isso se une nas práticas pedagógicas para que se dê atenção a situações pelas quais os cidadãos possam fazer julgamentos e tomar decisões frente a situações que envolvam a incerteza.

De acordo com as informações do sítio da SBEM, os pesquisadores do Grupo de Trabalho 12 (GT12) atuam e desenvolvem seus trabalhos na área de Educação Estatística - que tem como objetivo estudar e compreender como as pessoas ensinam e aprendem Estatística e Probabilidade. Tal interesse envolve os aspectos cognitivos e afetivos do ensino e da aprendizagem, além da epistemologia dos conceitos estatísticos e o desenvolvimento de métodos e materiais de ensino, etc., visando ao desenvolvimento do letramento estatístico (Scarlassari \& Lopes, 2019). Assim, compreendemos letramento estatístico como

a capacidade das pessoas de interpretar e avaliar criticamente informações estatísticas, argumentos relacionados a dados ou fenômenos estocásticos, que eles podem encontrar em diversos contextos, e quando relevante, (b) a capacidade delas discutirem ou comunicarem as suas reações a essas informações estatísticas, tais como a sua compreensão do significado da informação, suas opiniões sobre as implicações desta informação, ou as suas preocupações quanto à aceitabilidade de determinadas conclusões (Gal, 2020, p.2-3).

Para tal efeito, a EE utiliza-se de recursos teóricometodológicos de outras áreas, como, por exemplo, da Educação Matemática, Psicologia, Pedagogia, Filosofia e Matemática, além da própria Estatística. Por ser uma área de pesquisa recente, que ainda está se constituindo como um campo de estudo em ascensão, consideramos que a participação do GT12 nos eventos - Seminário Internacional de Pesquisa em Educação Matemática (SIPEM), Encontro Nacional de Educação Matemática (ENEM) e Encontro Brasileiro de Pós-Graduação em Educação Matemática (EBRAPEM) - é significativa para o crescimento e consolidação deste campo de estudo (Scarlassari \& Lopes, 2019).

Nessa linha, o presente artigo visa apresentar os resultados parciais de um estudo maior que reflete sobre o papel do uso das TD na EE, por meio de um levantamento bibliográfico com autores que se interterritorializam com um esforço de uso dessas tecnologias, nesta área de educação.

Dessa forma, surge a necessidade de investigar o que se tem produzido sobre EE mediado pelas TD, em publicações de sete revistas brasileiras, até a escrita deste ensaio; talvez, até o final da escrita deste, possam vir a ser publicadas novas edições que serão ampliadas em um outro momento.

Antes de efetivamente apresentarmos as descrição e análises dos dados obtidos a partir dos trabalhos selecionados, na seção que segue detalhamos os aspectos metodológicos que empregamos para a realização da investigação que permitiu estruturar este artigo.

\section{Aspectos Metodológicos}

A investigação ora apresentada é desenvolvida segundo a abordagem qualitativa, por meio da realização de um mapeamento crítico segundo os vieses da Metanálise, cujos estudos desenvolvem uma "análise crítica de um conjunto de estudos já realizados, tentando extrair deles informações adicionais que permitam produzir novos resultados, transcendendo aqueles anteriormente obtidos" (Fiorentini \& Lorenzato, 2007, p.71).

Com essa perspectiva, voltam-se as atenções para as pesquisas acadêmicas, por meio da realização de um estudo de abordagem qualitativa, bibliográfico e exploratórioinvestigativo, caracterizado como Metanálise (Fiorentini \& Lorenzato, 2007; Melo, 2013). Para tanto, foram analisados alguns textos em Educação Estatística que tiveram por objeto de investigação aspectos relacionados ao uso das Tecnologias 
Digitais, publicados em revistas brasileiras no período de 2011 a 2019, tendo sido acompanhados quanto à publicação de dossiês temáticos pelo grupo de pesquisa. Seguindo essa opção, foram selecionadas, respectivamente: Boletim de Educação Matemática On-Line (Bolema - ISSN 19804415 - A1), Revista Eletrônica Vydia (Vydia - ISSN 21764603 - A2), Educação Matemática Pesquisa (EMP/PUCSP - ISSN 1983-3156 - A2), Revista de Educação Matemática e Tecnológica Ibero-americana (Em Teia - ISSN 21779309 - B1), Revista de Ensino de Ciências e Matemática (Rencima - ISSN 2179-426X - A2 ), Revista Eletrônica de Educação Matemática (Revemat - ISSN 1981-1322 - A2), todas pertencentes à Plataforma Sucupira, Qualis Periódicos - Evento de classificação (triênio 2011-2016), área de ensino e classificação A1; A2 e B1. E, ainda, a Revista Brasileira de Educação em Ciências e Educação Matemática (ReBECEM e- ISSN 2594-9179 - ) que não consta no Qualis atual.

O mapeamento crítico foi desenvolvido por meio de um universo definido de pesquisas acadêmicas que investigaram aspectos relacionados à $\mathrm{EE}$ e às $\mathrm{TD}$, ou seja, visitamos o universo da revista Bolema, Vydia, EMP/PUCSP, Em Teia, REnCiMa, Revemat e ReBECEM. Portanto, na tecitura deste artigo, realizado a partir dos dados obtidos em fontes documentais (Ludke \& André, 2013), foram definidas sete revistas. A escolha do recorte espacial e temporal pode ser justificada com base nos resultados obtidos na investigação, selecionados e descritos no Quadro 1.

Quadro 1 - Relação das revistas que publicaram cadernos temáticos no período de 2011 a 2019

Boletim de Educação Matemática (BOLEMA). A revista foi avaliada em A1 no Qualis de Ensino de 2013-2016, e analisamos todos os textos da edição temática - Educação Estatística, disponíveis online no volume 24, número 39 e 40, 2011.

Revista Eletrônica Vidya (VIDYA). Este periódico foi avaliado em A2 no Qualis de Ensino de 2013-2016, e nele analisamos todos os textos da edição especial sobre o Ensino de Probabilidade e Estatística publicados e disponíveis online no volume 36, número 2, 2016.

Educação Matemática Pesquisa (PUCSP). O periódico foi avaliado no Qualis de Ensino 2013-2016 como A2 e consideramos o número temático - Educação Estatística, disponível online no volume 18, número 3, 2016.

Revista de Educação Matemática e Tecnológica Iberoamericana (EM TEIA). Esta revista foi avaliada como B1 no Qualis de Ensino de 2013-2016, em que consideramos seu acervo disponível online e cujo período é de 1979 a 2015.

Revista de Ensino de Ciências e Matemática (REnCiMa). A revista é avaliada como A2 no Qualis de Ensino de 20132016 e, para este trabalho, analisamos todos os textos da edição especial - Educação Estatística, disponíveis online no volume 9, número 2, 2018.

Revista Eletrônica de Educação Matemática (REVEMAT). A revista foi avaliada em A2 no Qualis de Ensino de 2013-2016 e analisamos todos os textos da edição especial - Educação Estatística, disponíveis online no volume 14, 2019.
Revista Brasileira de Educação em Ciências e Educação Matemática (ReBECEM). A revista foi avaliada em B2 no Qualis de Ensino de 2013-2016, e analisamos todos os textos da edição especial - Pesquisas em Educação Financeira e Educação Estatística, disponíveis online no volume 3, número, 2, 2019.

Fonte: Os autores (2021)

Cada artigo foi analisado e fundamentado utilizando procedimentos da Análise de Conteúdo (AC), de Bardin (1977), aplicados também por Franco (2012), que tem por objetivo a busca do sentido ou dos sentidos de um texto. Para Bardin, a Análise de Conteúdo é

um conjunto de técnicas de análise das comunicações visando obter, por procedimentos, sistemáticos e objetivos de descrição do conteúdo das mensagens, indicadores (quantitativos ou não) que permitam a inferência de conhecimentos relativos às condições de produção/recepção (variáveis inferidas) destas mensagens. (Bardin, 1977, p.42).

Convém ressaltar que a Análise de Conteúdo foi um dos métodos de análise desenvolvido nas metodologias dos artigos das revistas selecionadas para este corpus. Os materiais clássicos da $\mathrm{AC}$ são textos escritos que já foram utilizados para algum outro propósito, neste caso, as edições especiais versam sobre Educação Estatística. Todos esses textos, contudo, podem ser reinterpretados para fornecer respostas às perguntas do pesquisador (Bauer \& Gaskell, 2008).

Com relação à análise de resultados, faremos em três etapas. Na primeira, a identificação será realizada de modo que possamos apresentar o uso das Tecnologias Digitais na implementação da Educação Estatística, nos diferentes contextos escolares. Na segunda etapa, iremos tabular e categorizar os dados coletados nos artigos selecionados, nos sítios das revistas, de modo que possamos identificar a produção científica da EE com uso de TD. De posse dessas informações, na terceira, pretende-se discutir e analisar as mensagens representadas nos textos das revistas científicas brasileiras selecionadas. Para este artigo, nosso foco está centrado na segunda etapa.

\section{Descrição e Análise dos Dados}

Descrevemos, a seguir, os primeiros resultados obtidos. Assim, reconhecemos o campo de estudo por meio do levantamento dos textos publicados e selecionados para compor o corpus a partir das revistas selecionadas, conforme apresentamos a seguir.

Quadro 2 - Textos publicados e selecionados para compor o corpus

\begin{tabular}{|l|c|c|}
\hline \multicolumn{1}{|c|}{ Revista } & $\begin{array}{c}\text { Textos } \\
\text { Encontrados }\end{array}$ & $\begin{array}{c}\text { Textos } \\
\text { Selecionados }\end{array}$ \\
\hline BOLEMA & 26 & 03 \\
\hline VYDIA & 23 & 02 \\
\hline EMP & 23 & - \\
\hline EM TEIA & 30 & - \\
\hline REMCIMA & 23 & - \\
\hline REVEMAT & 30 & - \\
\hline REBECEM & 26 & 02 \\
\hline
\end{tabular}

Fonte: Os autores. 
Como pode ser visto no Quadro 2, a partir da identificação desses textos, nas sete edições temáticas que versam sobre TDIC na Educação Estatística em revistas brasileiras, foi realizada a leitura dos 181 textos publicados, restando para análise apenas sete textos que formaram o corpus da análise de produções científicas brasileiras. Para tanto, a seleção dos estudos para construir o corpus de estudos foi definida seguindo alguns critérios de inclusão e exclusão, observados concomitantemente.

Como critérios de inclusão, foram levados em consideração: (a) parâmetros linguísticos (idioma em língua portuguesa) e cronológico (2011 -2019), (b) artigos científicos sobre o tema em questão, e (c) estudos empíricos que apresentam considerações sobre as relações do uso pedagógico das tecnologias no ensino da Educação Estatística. Como critérios de exclusão, determinamos: (a) trabalhos de revisão de literatura, e (b) investigações que não se pautavam, especificamente, em estudos empíricos do uso pedagógico das tecnologias atrelados ao campo da Educação Estatística.

Ao proceder à leitura das produções científicas,

organizamos o segundo quadro, visando identificar os autores e os títulos dos textos, os objetivos e o contexto. A seguir, encontram-se a classificação e a organização das produções científicas.

Quadro 3 - Textos selecionados sobre TDIC na EE

\begin{tabular}{|c|c|c|c|c|}
\hline Código & Título & Autor & Objetivo & Contexto \\
\hline T01 & $\begin{array}{l}\text { O Uso de Simuladores e a } \\
\text { Tecnologia no Ensino da } \\
\text { Estocástica. }\end{array}$ & 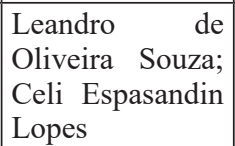 & $\begin{array}{l}\text { Investigar as contribuições que a inserção } \\
\text { da tecnologia pode trazer à educação } \\
\text { estocástica. }\end{array}$ & $\begin{array}{l}\text { Um grupo formado } \\
\text { por quatro alunas. }\end{array}$ \\
\hline T02 & $\begin{array}{l}\text { Interpretação de Dados a partir } \\
\text { da Utilização de Ferramentas } \\
\text { do Software TinkerPlots. }\end{array}$ & \begin{tabular}{|l|} 
Olga Cristina \\
Teixeira Lira; \\
Carlos Eduardo \\
F. Monteiro \\
\end{tabular} & $\begin{array}{l}\text { Investigar a interpretação de dados com } 12 \\
\text { estudantes do } 7^{\circ} \text { ano do Ensino Fundamental } \\
\text { que possuem familiaridade com ambientes } \\
\text { computacionais. }\end{array}$ & $\begin{array}{l}12 \text { estudantes, entre } \\
11 \text { e } 12 \text { anos de idade, } \\
\text { do } 7^{\circ} \text { Ano do Ensino } \\
\text { Fundamental. }\end{array}$ \\
\hline T03 & $\begin{array}{l}\text { Reflexão sobre } \\
\text { as Características } \\
\text { Sociodemográficas, } \\
\text { Educacionais, do uso de } \\
\text { Tecnologias e das Práticas } \\
\text { Docentes de Professores de } \\
\text { Estatística no Ensino Superior } \\
\text { no Brasil. }\end{array}$ & $\begin{array}{l}\text { Ailton Paulo de } \\
\text { Oliveira Júnior }\end{array}$ & $\begin{array}{l}\text { Apresentar, através das características } \\
\text { sociodemográficas, educacionais o uso de } \\
\text { tecnologias e de práticas docentes de } 334 \\
\text { professores que ministram disciplinas de } \\
\text { Estatística em cursos das áreas de Exatas, } \\
\text { Humanas e Saúde de instituições públicas e } \\
\text { privadas do Ensino Superior. }\end{array}$ & $\begin{array}{l}\text { Foram sujeitos } \\
\text { da pesquisa } 334 \\
\text { professores. }\end{array}$ \\
\hline T04 & $\begin{array}{l}\text { O uso do software gratuito } \\
\text { GeoGebra no ensino e na } \\
\text { aprendizagem de Estatística e } \\
\text { Probabilidade. }\end{array}$ & $\begin{array}{l}\text { Humberto José } \\
\text { Bortolossi }\end{array}$ & $\begin{array}{l}\text { Sensibilizar os profissionais que atuam com } \\
\text { a formação de professores de Matemática, } \\
\text { no sentido de que estes considerem o uso } \\
\text { do GeoGebra nas disciplinas de Estatística, } \\
\text { preferencialmente a outros softwares mais } \\
\text { técnicos de Estatística. }\end{array}$ & $\begin{array}{l}\text { Não explicitado o } \\
\text { contexto. }\end{array}$ \\
\hline T05 & $\begin{array}{l}\text { Interações entre construção } \\
\text { e interpretação de gráficos } \\
\text { estatísticos em projetos de } \\
\text { modelagem matemática } \\
\text { com uso de Tecnologias de } \\
\text { Informação e Comunicação. } \\
\end{array}$ & $\begin{array}{l}\text { Leandro do } \\
\text { Nascimento } \\
\text { Diniz; } \\
\text { José António } \\
\text { Fernandes }\end{array}$ & $\begin{array}{l}\text { Analisa a leitura, construção e interpretação } \\
\text { de gráficos estatísticos em projetos de } \\
\text { modelagem com uso das Tecnologias de } \\
\text { Informação e Comunicação. }\end{array}$ & $\begin{array}{l}\text { Alunos de seis } \\
\text { turmas, matriculados } \\
\text { em quatro cursos } \\
\text { técnicos. }\end{array}$ \\
\hline T06 & $\begin{array}{l}\text { Uso de Tecnologias } \\
\text { Digitais em pesquisas de } \\
\text { opinião: discussões sobre } \\
\text { o componente afetivo do } \\
\text { letramento estatístico a partir } \\
\text { do modelo de Iddo Gal. } \\
\end{array}$ & $\begin{array}{l}\text { Felipe Júnior de } \\
\text { Souza Oliveira; } \\
\text { Diogo Alves de } \\
\text { Faria Reis }\end{array}$ & $\begin{array}{l}\text { Investigar e analisar o uso das TD (suas } \\
\text { contribuições e limitações) em um projeto } \\
\text { educativo de pesquisa de opinião para um } \\
\text { processo de aprendizagem em Estatística } \\
\text { de alunos do oitavo ano do Ensino } \\
\text { Fundamental. }\end{array}$ & $\begin{array}{l}16 \text { alunos do oitavo } \\
\text { ano do Ensino } \\
\text { Fundamental. }\end{array}$ \\
\hline T07 & $\begin{array}{l}\text { Uso de planilhas eletrônicas } \\
\text { para a aprendizagem de } \\
\text { Estatística. }\end{array}$ & $\begin{array}{l}\text { Kátia Alves } \\
\text { Campos; } \\
\text { Roger Henrique } \\
\text { Silva; } \\
\text { Roberto Luiz de } \\
\text { Azevedo }\end{array}$ & $\begin{array}{l}\text { Relatar a experiência de um minicurso em } \\
\text { que conteúdos de Estatística são tratados } \\
\text { com auxílio de planilhas eletrônicas, com } \\
\text { foco na desmistificação da estatística básica } \\
\text { e adaptação desse conteúdo para tomada de } \\
\text { decisões. }\end{array}$ & $\begin{array}{l}\text { Alunos do curso } \\
\text { técnico de nível } \\
\text { médio em Alimentos. }\end{array}$ \\
\hline
\end{tabular}

Fonte: Os autores.

Realizamos a leitura minuciosa dos resumos das 7 (sete) produções científicas, visto que também possuíam maior proximidade com o tema de pesquisa se comparadas às demais produções.
Em relação ao âmbito dos participantes da pesquisa, foi possível perceber que os textos tiveram como envolvidos estudantes do Ensino Básico (T01, T02 e T06), Ensino Técnico (T05 e T07) e professores que lecionam disciplinas destinadas 
ao Ensino Superior (T03). Apenas o texto T04 não explicita o contexto em que a pesquisa foi desenvolvida. Tal descrição nos permite inferir que os textos em EE não têm se dedicado apenas a um ambiente de investigação. Pelo contrário, há presença de vários níveis de ensino: Ensino Fundamental, Ensino Médio, Ensino Técnico e Ensino Superior.

Esses contextos sinalizaram que há uma mensagem intencional implícita nos conteúdos analisados, ou seja, foi abordada a necessidade de uma intencionalidade estatística na seleção e utilização das TD, para desenvolver o entendimento dos estudantes em atividades de tarefas estatísticas e discutir elementos nucleares da prática pedagógica de professores que contribuem para a melhoria da qualidade das aprendizagens da EE dos estudantes.

No que diz respeito aos procedimentos metodológicos utilizados nessas pesquisas, apresentamos no Quadro 4 os procedimentos metodológicos que são assumidos nos textos.

Quadro 4 - Delineamento de pesquisa

\begin{tabular}{|l|l|}
\hline \multicolumn{1}{|c|}{ Abordagem } & \multicolumn{1}{c|}{ Texto em que é citado } \\
\hline Qualitativa & T01, T05, T06 \\
\hline Qualiquantitativa & T03 \\
\hline Sem menção & T02, T04, T07 \\
\hline
\end{tabular}

Fonte: Dados da pesquisa.

Por meio do Quadro 4, podemos observar que quatro textos assumem claramente sua opção, quais sejam: T01, T03, T05 e T06. Nos demais, não fica explícito o delineamento de pesquisa assumido. Desses que assumiram abordagem metodológica, percebemos que os autores dos textos procuraram compreender o "universo de significados, motivos, aspirações, crenças, valores e atitudes, o que corresponde a um estudo mais profundo das relações, dos processos e dos fenômenos" (Minayo, 2004, p.21-22). Com isso, o pesquisador teve a preocupação de interpretar e compreender as falas e as informações produzidas (Rocha \& Barreto, 2008) a partir dos diálogos e da apresentação de materiais, elaborados e realizados pelos estudantes e professores que colaboraram com a pesquisa.

Os instrumentos de produção de dados utilizados nesses textos foram: gravação, observação, questionário, documentos e entrevistas. Passamos ao Quadro 5, em que apresentamos os instrumentos de produção de dados.

Quadro 5 - Instrumentos de produção de dados

\begin{tabular}{|l|l|}
\hline \multicolumn{1}{|c|}{ Instrumentos } & \multicolumn{1}{c|}{ Texto em que é citado } \\
\hline Gravação & T01, T06 \\
\hline Observação & T02, T05, T06 \\
\hline Questionário & T03, T07 \\
\hline Entrevista & T05 \\
\hline Documentos & T05 \\
\hline Vídeo & T02 \\
\hline Não menciona & T04 \\
\hline Fonte: Dados da pesquisa. &
\end{tabular}

Conforme o Quadro 5, verificamos que os trabalhos T01, T02, T03, T05, T06 e T07 apresentam os instrumentos de produção de dados. Isso denota que os textos trazem uma mensagem coerente interna entre o tipo de análise, instrumentos utilizados e a análise realizada, apesar de o texto T04 não explicitar os instrumentos de produção de dados. Constatamos que o uso da observação com maior incidência nos textos se deve ao fato de possibilitar ao pesquisador conhecer, com maior riqueza de detalhes, as características dos grupos e/ou participantes da pesquisa (Gil, 2009).

\subsection{Tecnologias Digitais na Educação Estatística: usos e finalidades}

Em relação ao uso das TD e após a análise realizada, foi possível identificar um diferente interesse do uso dessas tecnologias, no que se refere à forma de apresentação do objetivo de cada artigo. Para melhor exposição, serão apresentadas em dois blocos essas identificações. Bloco 1: ênfase sobre os professores; Bloco 2: ênfase sobre os estudantes.

Bloco 1 - Referente ao primeiro bloco, os autores do artigo (T01) objetivaram investigar as contribuições que a inserção de tecnologia pode trazer à educação estocástica - portanto, trata-se de uma análise sobre a prática do professor. Em T03, os autores mantêm o interesse em identificar características sociodemográficas educacionais de práticas docentes de 334 professores; T04 buscam sensibilizar profissionais que atuam com a formação de professores de Matemática para o uso de GeoGebra. É possível assegurar que há interesse em observar e analisar o ensino.

Bloco 2 - Neste segundo grupo, percebemos a semelhança de ações apresentadas em T02, T05, T06 e T07, pois todos estes objetivos foram constituídos com interesse de analisar o uso de TD, sob o ponto de vista dos estudantes (por exemplo: ensino fundamental, cursos técnicos). Há um foco visível sobre melhorias de aprendizagens presente neste grupo.

A partir da leitura dos sete trabalhos analisados, ao longo deste artigo, das competências esperadas pelo ensino de Estatística, Probabilidade e Combinatória, do Ensino Infantil ao Superior, de modo que os estudantes possam se valer desses recursos computacionais para auxiliar no tratamento de dados e na leitura de mundo ao utilizarem conceitos estatísticos, acreditamos que uso das Tecnologias Digitais podem promover o acesso, a apropriação e o desenvolvimento probabilístico e combinatório embasados em considerações extraídas de ambientes computacionais (Damin et al., 2019). Tal uso pode favorecer a formação dos estudantes de modo a “[...] estarem atualizados em relação às novas tecnologias da informação e se instrumentalizarem para as demandas sociais presentes e futuras" (Brasil, 1998, p.96).

Além disso, apenas o uso das TD na prática pedagógica não garante a construção de conhecimentos no campo da Educação Estatística, sendo necessária uma finalidade pedagógica para orientar o trabalho de professores e alunos com o computador (Damin et al., 2019; Moraes, 2011). Segundo Lopes (2008, p. 2), é necessário desenvolver uma prática pedagógica “[...] 
em que os estudantes realizem atividades as quais considerem seus contextos e possam observar e construir os eventos possíveis, por meio de experimentação concreta, de coleta e de organização de dados". Ou seja, "é necessário que o professor reflita e entenda as suas escolhas, metodológicas e pedagógicas, de forma que possa analisar como as tecnologias digitais educacionais podem auxiliar em sala de aula" (Damin et al., 2019, p. 53).

Assim, as TD podem caracterizar um instrumento de apoio à prática pedagógica, uma vez que favorecem a tomada de decisão e de compreensão de conceitos estatísticos, probabilísticos e combinatórios por parte dos estudantes. Desse modo, a aprendizagem de conceitos estatísticos, probabilísticos e combinatórios vai depender da forma como o professor os usa em sala de aula e da "[...] ação interiorizada dos alunos, pelo significado que dão às suas ações, às formulações que enunciam, às verificações que realizam" (Lorenzato, 2006, p. 81).

Tendo em vista as potencialidades didático-pedagógicas das TD nos processos de ensino e de aprendizagem na/para Educação Estatística, entendemos que o uso intencional desses recursos tecnológicos na prática pedagógica tem como finalidade fazer com que estudantes, em diferentes níveis de ensino, possam construir uma abordagem de conceitos, fatos e procedimentos presentes em situações-problema da vida cotidiana, das ciências e da tecnologia, bem como desenvolver habilidades para coletar, representar, interpretar e organizar dados de uma variedade de contextos, de maneira a fazer julgamentos bem fundamentados e tomar as decisões adequadas. Isso inclui raciocinar e utilizar conceitos, representações e índices estatísticos para descrever, explicar e predizer fenômenos (Brasil, 2017).

\section{Considerações Finais}

Este trabalho teve como objetivo realizar um mapeamento dos textos publicados nas seguintes revistas: Boletim de Educação Matemática (BOLEMA), Revista Eletrônica Vydia (VYDIA), Educação Matemática Pesquisa (PUCSP), Revista de Educação Matemática e Tecnológica Iberoamericana (EM TEIA), Revista de Ensino de Ciências e Matemática (REnCiMa), Revista Eletrônica de Educação Matemática (REVEMAT) e Revista Brasileira de Educação em Ciências e Educação Matemática (ReBECEM) sobre os usos das Tecnologias Digitais na Educação Estatística. As edições especiais publicadas pelas revistas com foco em Educação Estatística têm por objetivo divulgar textos sobre os processos de ensinar e de aprendizagem de Estatística, Combinatória e Probabilidade, o que envolve a epistemologia dos conceitos estatísticos, combinatórios e probabilísticos, o desenvolvimento de estratégias de ensino, bem como os aspectos cognitivos e afetivos envolvidos nestes processos.

Analisamos sete revistas que publicaram um total de 181 textos. Desse total, apenas 7 (equivalente a 3,87\%) trabalhos investigaram o uso das $\mathrm{TD}$, sendo três desses com enfoque voltado ao ensino e quatro às aprendizagens dos estudantes. Esses textos foram avaliados em categorias que permitiram identificar as formas de inserção das TD na EE, tais como: níveis de ensino; objetivos; procedimentos metodológicos e instrumentos de produção de dados. Nosso resultado amplia dados de levantamentos anteriores (Campos, Silva \& Azevedo, 2019; Oliveira \& Reis, 2019; Bortolossi, 2016; Diniz \& Fernandes, 2016), mas concorda com a indicação destes autores de que a temática das TD ainda tem inserção tímida na área de Educação Estatística.

Como toda busca, destacamos o limite de tempo destinado a estas discussões que envolvem o campo de estudo, a Educação Estatística Tecnológica, representada somente em sete textos de um total de 81, enquanto poderia ocupar lugar de destaque, o que indica, certamente, um campo fértil para a produção científica. Situamos como possibilidade a continuidade dos estudos e a análise das temáticas subjacentes às obras que compõem as revistas e/ou eventos da área, por exemplo, ENEM, EBRAPEM, SIPEM, que apresentam Grupo de Trabalho/Discussão com foco na EE. Como perspectiva mais abrangente, há o desejo de ampliar as compreensões e os debates sobre a mensagem que essas ocupam na Educação Estatística.

\section{Referências}

Aresta, M, Pedro, L \& Santos, C. (2015). Mobile learning and higher education: A theoretical overview. Journal of Mobile Multimedia, 11(1-2), 147-156.

Bardin, L. (1977). Análise de conteúdo. Lisboa: Edições 70.

Barreto, R.G. (2006). As Tecnologias da Informação e da Comunicação na formação de professores. Revista Brasileira de Educação, 11(31),31-42.

Bates, T. (2017). Educar na era digital: Design, ensino e aprendizagem. Tradução João Mattar. São Paulo: Artesanato Educacional.

Batista, J. (2011). O uso das Tecnologias da Comunicação no ensino superior. (Doctoral dissertation - Universidade de Aveiro).

Bauer, M.W. \& Gaskell, G. (2008). Pesquisa qualitativa com texto, imagem e som: Um manual prático. Petrópolis, RJ: Vozes.

Becker, S.A. (2017). NMC horizon report: 2017 higher education edition. Austin: The New Media Consortium.

Bortolossi, H.J. (2016). O uso do software gratuito GeoGebra no ensino e na aprendizagem de Estatística e Probabilidade. VIDYA, 36(2), 429-440.

Brasil. (2017). Base Nacional Comum Curricular - BNCC. Educação é a base. Brasília: MEC.

Brasil. (1988). Parâmetros Curriculares Nacionais: Matemática. $3^{\circ}$ e $4^{\circ}$ ciclos do Ensino Fundamental. Brasília, DF: MEC.

Campos, K.A., Silva, R.H. \& Azevedo, R.L. (2019). Uso de Planilhas Eletrônicas para a aprendizagem de Estatística. ReBECEM, Cascavel (PR), 3(2), 224-240.

Cazorla, I.M., Silva, A.V. Jr. \& Santana, E.R.S. (2018). Reflexões sobre o ensino de variáveis conceituais na educação básica. REnCiMa, 9(2), 354-373. 
Cordeiro, S.F.N. \& Bonilla, M.H.S. (2015). Tecnologias Digitais Móveis: Reterritorialização dos cotidianos escolares. Educar em Revista, Curitiba (PR), 56, 259-275.

Damin, W., Santos Junior, G., Neto, J.C., Robim, B.N., Palharini, A. Souza. \& Pereira, Rudolph dos Santos Gomes. (2019). As Tecnologias Digitais educacionais e o ensino de Estatística e Probabilidade. Rev. Ens. Educ. Cienc. Human., 10(1), 53-57.

Diniz, L. N. \& Fernandes, J. A. (2016). Interações entre construção e interpretação de Gráficos Estatísticos em Projetos de Modelagem Matemática com uso de Tecnologias de Informação e Comunicação. VIDYA, 36(2), 457-475.

Estevam, E.J.G. (2010). (Res)significando a Educação Estatística no Ensino Fundamental: Análise de uma sequência didática apoiada nas Tecnologias de Informação e Comunicação. (Master's thesis, Universidade Estadual Paulista, Faculdade Ciências e Tecnologia).

Ferreira, N.S.A. (2002). As pesquisas denominadas 'estado da arte'. Educação \& Sociedade, Campinas (SP), 23(79), 257272 .

Fiorentini, D. (1994). Rumos da pesquisa brasileira em Educação Matemática: O caso da produção científica em cursos de pósgraduação. (Doctoral dissertation, Faculdade de Educação, Universidade Estadual de Campinas).

Fiorentini, D. \& Lorenzato, S. (2007). Investigação em educação matemática: Percursos teóricos e metodológicos. Campinas: Autores Associados.

Franco, M.L.P.B. (2012). Análise de conteúdo. Brasília: Líber Livro.

Gal, I. (2002). Adult statistical literacy: Meanings, components, responsibilities. International Statistical Review,1(70), 1-25.

Gil, A.C. (2012). Métodos e técnicas de pesquisa social. São Paulo: Atlas.

Lira, O.C.T. \& Monteiro, C.E.F. (2011). Interpretação de dados a partir da utilização de ferramentas do Software TinkerPlots. Bolema, Rio Claro (SP), 24(40), 765-788.

Lopes, C.E. (1998). A Probabilidade e a Estatística no Ensino Fundamental: Uma análise curricular. (Master's thesis, Universidade Estadual de Campinas-SP).

Lorenzato, S. (Org.). (2006). O Laboratório de Ensino de Matemática na formação de professores. Campinas, SP: Autores Associados.

Ludke, M. \& André, M.E.D.A. (2013). Pesquisa em educação: Abordagens qualitativas. Rio de Janeiro: EPU.

Melo, M.V. (2013). As práticas de formação no Estágio Curricular Supervisionado na Licenciatura em Matemática: O que revelam as pesquisas acadêmicas brasileiras na década 2001-2010. (Doctoral dissertation, Universidade Estadual de Campinas, SP.

Moraes, L.R. (2011). Desenvolvimento de um sistema modelo para ensino aprendizagem de Estatística nas séries iniciais. Santo Ângelo: Universidade Regional Integrada do alto Uruguai e das Missões.

Moraes, R. (2003). Uma tempestade de luz: A compreensão possibilitada pela Análise Textual Discursiva. Revista Ciência \& Educação, 9(2).
Norman, H. et al. (2013). A review on the use and perceived effects of mobile blogs on learning in Higher Educational settings. Asian Social Science, Ontario, 10(1), 209-222.

Oliveira Jr, A.P. (2011). Reflexão sobre as Características Sociodemográficas, Educacionais do uso de tecnologias e das práticas docentes de professores de Estatística no Ensino Superior no Brasil. Bolema, Rio Claro (SP), 24(39), 387-412.

Oliveira, F.J.S. \& Reis, D.A.F. (2019). Uso de Tecnologias Digitais em pesquisas de opinião: Discussões sobre o componente afetivo do Letramento Estatístico a partir do modelo de Iddo Gal. ReBECEM, Cascavel (PR), 3(2), 199-22.

Pinto, M. \& Leite, C. (2020). As Tecnologias Digitais nos percursos de sucesso acadêmico de estudantes não tradicionais do Ensino Superior. Educação Pesquisa, São Paulo, 46, e216818.

Pombo, L. (2016). The use of Communication Technologies in Higher Education in Portugal: Best practices and future trends. In M.J. Marcelino, A.J. Mendes \& M.C.A. Gomes (Eds.). ICT in education: Multiple and inclusive perspectives (pp. 1-20). Cham: Springer International.

Santos, A.A. (2019). A construção do Letramento Estatístico em estratégias com o uso de Tecnologias Digitais em aulas de Estatística de Cursos de Graduação. (Master's thesis, Pontifícia Universidade Católica de São Paulo).

Santos, R.M. (2014). A evolução histórica da educação estatística e da sua pesquisa no Brasil. [Communication]. II Encontro Nacional de Pesquisa em História da Educação Matemática. Annual Conference. Bauru, SP. http://www2.fc.unesp.br/ enaphem/sistema/trabalhos/1.pdf

Scarlassari, N.T. \& Lopes, C.E. (2019). Mapeamento dos trabalhos publicados nas seis primeiras edições do SIPEM pelo Grupo de Trabalho em Educação Estatística (GT12) da SBEM. REVEMAT, Florianópolis, SC, 14, 1-17. Edição Especial Educação Estatística.

Selwyn, N. (2016). Is technology good for education? Cambridge: Polity Press.

Silva, C.M.O. (2006). Criança-professor-computador: Possibilidades interativas e sociais na sala de aula. Revista de Humanidades, Fortaleza, 21(2), 151-136.

Sleeman, J., Lang, C. \& Lemon, N. (2016). Social media challenges and affordances for international students: Bridges, boundaries, and hybrid spaces. Journal of Studies in International Education, Washington, DC, 20(5), 391-415.

Souza, L.O. \& Lopes, C.E. (2011). O uso de Simuladores e a Tecnologia no Ensino da Estocástica. Bolema, Rio Claro (SP), 24(40), 659-677.

Stevenson, M.E. \& Hedberg, J.G. (2017). Mobilizing learning: A thematic review of apps in K-12 and Higher Education. Interactive Technology and Smart Education, Bingley, 14(2), 126-137.

Valim, J.C.M. (2019). A produção de vídeos por estudantes da Educação Básica: Uma possibilidade de abordagem metodológica no ensino de Estatística. Pato Branco: UTFPR. (Master's thesis, Universidade Tecnológica Federal do Paraná). 